Bali Medika Jurnal.

Vol 7 No 2, 2020: 1-8

ISSN : 2615-7047

DOI: https://doi.org/10.36376/bmj.v7i2

Disubmit 22 September 2020

Diterima 16 November 2020

\title{
GLASGOW COMA SCALE (GCS) DAN TEKANAN DARAH SISTOLIK SEBAGAI PREDIKTOR OUTCOME PASIEN CEDERA KEPALA
}

\section{GLASGOW COMA SCALE AND SYSTOLIC BLOOD PRESSURE AS OUTCOME PREDICTORS FOR HEAD INJURY PATIENTS}

\author{
Agnes Silvina Marbun ${ }^{1}$, Elida Sinuraya ${ }^{2}$, Amila $^{3}$, Galvani Volta Simanjuntak ${ }^{4}$ \\ Departmen Keperawatan, Fakultas Farmasi dan Ilmu Kesehatan, \\ Universitas Sari Mutiara Indonesia, Indonesia ${ }^{1,2,3}$
}

\begin{abstract}
ABSTRAK
Dikarenakan angka kematian pasien cedera kepala tinggi, sehingga diperlukan penilaian awal yang akurat untuk memprediksi hasil dan asuhan keperawatan yang sesuai dengan kondisi pasien. Tujuan penelitian ini adalah untuk mengetahui GCS, tekanan darah sistolik, dan frekuensi pernapasan yang dapat menjadi prediktor mortalitas pasien cedera kepala di RSUP Haji Adam Malik Medan. Desain penelitian ini adalah observasional analitik dengan pendekatan retrospektif. Populasi dalam penelitian ini adalah rekam medis pasien cedera kepala bulan Januari-Desember 2018 di RSUP Haji Adam Malik Medan. Pengambilan sampel dilakukan dengan teknik purposive sampling dengan kriteria: memiliki skor GCS, tekanan darah sistolik, dan frekuensi pernafasan pada saat pasien masuk IGD dan bukan pasien pindahan. Hasil uji regresi logistik menunjukkan adanya hubungan GCS (p 0,000; OR 3,299) dan tekanan darah ( 0 0,024; OR 1,044) terhadap kematian pasien cedera kepala. Kesimpulan bahwa GCS dan tekanan darah secara statistik dapat meningkatkan prediksi mortalitas pada pasien cedera kepala.
\end{abstract}

Kata Kunci: Glasgow Coma Scale, Cedera Kepala, Mortalitas, Frekuensi Pernapasan, Tekanan Darah Sistolik

\section{ABSTRACT}

Because of the relatively high mortality rate in head injury patients requires an accurate initial assessment to predict the outcome and appropriate nursing interventions in accordance with patient's condition. This study examined Glasgow Coma Scale (GCS), systolic blood pressure, and respiratory rate as mortality predictors in patients with head injury at Haji Adam Malik Central Hospital in Medan. It was an analytical observational study with retrospective approach. The research population was medical record of head injury patients in the period of January - December 2018 in Haji Adam Malik Central Hospital. The sampling was taken by purposive sampling technique with several criteria including: having a GCS score, systolic blood pressure, respiratory rate at the time the patients admitted to the emergency room and was not a transferred patient. The results of logistic regression analysis showed that there was a correlation between GCS score ( $p$ 0.000; OR 3.299) and systolic blood pressure (p 0.024; OR 1,044) toward mortality of head injury patients. It is concluded that GCS and systolic blood pressure statistically increase the prediction of mortality in patients with head injury. 
Bali Medika Jurnal.

Vol 7 No 2, 2020: 1-8

ISSN : 2615-7047

DOI: https://doi.org/10.36376/bmj.v7i2

Keywords: Glasgow Coma Scale, Head Injury, Mortality, Respiratory Rate, Systolic Blood Pressure

\begin{tabular}{ll}
\hline Alamat Korespondensi & $: \begin{array}{l}\text { Departmen Keperawatan, Fakultas Farmasi dan Ilmu } \\
\text { Kesehatan, Universitas Sari Mutiara Indonesia } \\
\text { Email }\end{array}$ \\
\hline
\end{tabular}

\section{PENDAHULUAN}

Cedera kepala merupakan faktor utama penyebab mortalitas dan morbiditas akibat trauma yang juga menimbulkan permasalahan di bidang ekonomi dan sosial (Areas dkk., 2019; Strnad, Borovnik Lesjak, Vujanović, \& Krizmarić, 2017). yang angka kejadiannya mengalami peningkatan dari 0,4\% menjadi 11,9\% (Kementrian Kesehatan RI, 2019). Akibat cedera kepala, 100ribu jiwa lebih meninggal dan 700ribu lebih membutuhkan perawatan intensif yang memerlukan biaya sekitar 60,43 juta US dollar setiap tahunnya (Aprilia, 2017; Putra, Indra, Sargowo, \& Fathoni, 2016).

Manajemen yang cepat dan tepat dapat menghindarkan pasien cedera kepala dari mortalitas dan morbiditas (Suwaryo, Wihastuti, \& Fathoni, 2016). Seorang perawat memiliki peran penting dalam manajemen pasien cedera kepala (Varghese, Chakrabarty, \& Menon, 2017). Seorang perawat dituntut bisa menilai setiap respon dan reaksi abnormal, mengenali prognosis baik dan buruk pada pasien cedera kepala (Suwaryo dkk., 2016).

Penilaian prognosis dapat dilakukan dengan mengobservasi hasil pemeriksaan standar yang dilakukan di IGD pada pasien cedera kepala seperti Skor GCS, tekanan darah sistolik dan frekuensi napas. GCS merupakan sebuah metode untuk mengukur tingkat kesadaran secara kuantitatif dengan mengobservasi respon membuka mata, verbal dan motorik. Skor GCS didapat dengan menjumlahkan tiap poin yang diperoleh dari ketiga aspek pemeriksaan tersebut dengan nilai terendah 3 dan tertinggi 15. Penelitian Baum, Entezami, Shah, \& Medhkour (2016) mendapatkan bahwa setiap penurunan satu nilai GCS berhubungan dengan $14 \%$ kematian. GCS merupakan prediktor evaluasi pada pelayanan trauma (Osler dkk., 2016).

Tekanan darah sistolik berhubungan dengan aliran darah ke otak (Guyton \& Hall, 2014). Aliran darah ke otak yang tidak adekuat berakibat timbulnya gangguan perfusi otak yang dapat meningkatkan risiko kematian (Sumarno, Hidajat, \& Rini, 2016). Hubungan tekanan arteri dan prognosis yang terbaik dinyatakan dengan tekanan sistolik $\geq 90 \mathrm{mmHg}$ (Sumarno dkk., 2016).

Frekuensi pernapasan manusia normalnya 12-24 kali per menit yang diatur oleh batang otak sehingga apabila terjadi pola dan frekuensi napas yang tidak biasa mungkin menggambarkan adanya gangguan di batang otak. Aktivitas pusat pernapasan dapat ditekan oleh pembengkakan otak yang timbul akibat cedera kepala (Guyton \& Hall, 2014). Frekuensi pernapasan memiliki hubungan yang bermakna terhadap luaran perawatan pada pasien cedera kepala dengan ketentuan $<12 \mathrm{kali} /$ menit atau $>24$ kali per menit memiliki luaran perawatan yang buruk (Ristanto, Indra, Poeranto, \& Rini, 2016). 
Beberapa penelitian terdahulu menunjukkan adanya variasi prediktor kematian pasien cedera kepala. Penelitian Bruijns, Guly, Bouamra, Lecky, \& Wallis (2014) bahwa frekuensi pernafasan merupakan prediktor yang baik untuk mengetahui outcome pasien cedera kepala, bersama dengan tekanan darah sistolik. Sedangkan penelitian Suwaryo dkk., (2016) bahwa frekuensi pernafasan tidak berhubungan dengan outcome pasien cedera kepala

Angka kematian akibat cedera kepala tinggi, oleh karena itu penilaian awal yang akurat sangat penting dilakukan guna memberikan informasi mengenai prognosis pada pasien cedera kepala. penilaian awal yang akurat diharapkan dapat membantu memprediksi outcome dan tatalaksana sesuai keadaan pasien. Pada artikel ini, penulis akan menyajikan temuan GCS, tekanan darah sistolik, dan frekuensi napas sebagai faktor predictor outcome pasien cedera kepala.

\section{METODE PENELITIAN}

Rancangan yang digunakan pada penelitian ini adalah analitik observasi dengan pendekatan retrospektif yang dilakukan di Instalasi rekam medis RSUP H. Adam Malik Medan. Populasi penelitian adalah rekam medis pasien cedera kepala periode Januari-Desember 2018 sebanyak 433. Sampel diambil dengan teknik purposive sampling dengan kriteria: terdapat data skor GCS, nilai tekanan darah sistolik, frekuensi napas, data outcome pasien serta bukan rekam medis pasien rujukan. Berdasarkan kriteria tersebut, didapatkan sampel sebanyak 166. Penelitian ini telah disetujui oleh Komite Etik Penelitian Kesehatan Fakultas Kedokteran Universitas Muhammadiyah Sumatra Utara dengan nomor surat 393/KEPK/FKUMSU/2020.

Pengumpulan data menggunakan lembar observasi sebagai instrumen untuk mengidentifikasi skor GCS, nilai tekanan darah sistolik, frekuensi napas dan outcome pasien yang dilihat dari kondisi pasien setelah mendapat perawatan selama 7 hari, apakah pasien hidup atau meninggal. Skor GCS, nilai tekanan darah sistolik, frekuensi napas di ambil dari data hasil pengkajian awal saat pasien masuk IGD.

Analisis data yang digunakan adalah uji regresi logistik yang digunakan untuk melihat secara bersama-sama (simultan) apakah ketiga variabel (GCS, tekanan darah sistolik dan frekuensi pernapasan) berpengaruh secara signifikan terhadap outcome pasien cedera kepala dan untuk menentukan faktor mana yang paling dominan mempengaruhi outcome pasien cedera kepala.

\section{HASIL DAN PEMBAHASAN}

\section{HASIL PENELITIAN}

Tabel 1. Distribusi frekuensi berdasarkan jenis kelamin dan mortalitas $(\mathrm{N}=166)$

\begin{tabular}{lcc}
\hline \multicolumn{1}{c}{ Variabel } & F & \% \\
\hline Jenis kelamin & & \\
Laki-laki & 117 & 70.5 \\
Perempuan & 49 & 29.5 \\
Outcome & & \\
Hidup & 122 & 73.5 \\
Meninggal & 44 & 26.5 \\
\hline
\end{tabular}


Tabel 1 menunjukkan bahwa mayoritas responden berjenis kelamin laki-laki dengan outcome hidup setelah mengalami cedera kepala.

Tabel 2. Deskripsi variabel usia, GCS, Tekanan darah sistolik dan leukosit $(\mathrm{N}=166)$

\begin{tabular}{lccc}
\hline \multicolumn{1}{c}{ Variabel } & Min & Max & Mean \\
\hline Usia & 15 & 64 & 35.7 \\
GCS & 3 & 15 & 11,74 \\
Tekanan darah sistolik & 58 & 173 & 83,87 \\
Frekuensi napas & 9 & 35 & 23,93 \\
\hline
\end{tabular}

Tabel 2 menunjukkan bahwa bahwa rata-rata skor GCS 11,74 (3-15), ratarata nilai tekanan darah sistolik 83,87 (58-173) rata-rata frekuensi napas 23.93 (9$35)$.

Tabel 3. Hasil analisis variabel secara simultan

\begin{tabular}{cccc}
\hline Step & $\begin{array}{c}-2 \text { Log } \\
\text { likelihood }\end{array}$ & $\begin{array}{c}\text { Cox \& Snell R } \\
\text { Square }\end{array}$ & $\begin{array}{c}\text { Nagelkerke R } \\
\text { Square }\end{array}$ \\
\hline 1 & 47.762 & .581 & .847 \\
\hline
\end{tabular}

Tabel 3 menunjukkan bahwa secara bersama-sama (simultan), variabel GCS, tekanan darah sistolik dan frekuensi pernapasan dapat memprediksi sebesar $84,7 \%$ outcome pasien cedera kepala. $15,3 \%$ lainnya dipengaruhi oleh faktor lainnya.

Tabel 4. Hasil analisis regresi logistik

\begin{tabular}{lccc}
\hline \multicolumn{1}{c}{ Variabel } & B & pValue & OR \\
\hline GCS & -1.208 & .000 & 3.299 \\
Tekanan darah sistolik & -.043 & .024 & 1.044 \\
Frekuensi napas & -.088 & .351 & 1.093 \\
\hline
\end{tabular}

Tabel 4 menunjukkan bahwa variabel yang mempengaruhi outcome pasien cedera kepala secara signifikan adalah GCS $(0,000)$ dengan pola negative dan odd ratio sebesar 3,299 yaitu semakin rendah skor GCS, semakin meningkatkan resiko kematian pada pasien cedera kepala sebesar 3,299 kali dan tekanan darah sistolik $(0,024)$ dengan pola negative dengan odd ratio sebesar 1,044 yaitu semakin rendah tekanan darah sistolik,, semakin meningkatkan risiko mortalitas sebesar 1,044 kali. Dari tabel 4 dapat diketahui bahwa faktor dominan yang mempengaruhi outcome pasien cedera kepala adalah skor GCS.

\section{PEMBAHASAN}

Berbagai studi bervariasi tentang prevalensi usia pasien yang mengalami cedera kepala. Penelitian ini mendapatkan rentang usia yang mengalami cedera kepala adalah 15-64 tahun, sedangkan Kasmaei, Asadi, Zohrevandi, \& Raouf 
(2015) mendapatkan bahwa usia 20-60 lebih beresiko mengalami cedera kepala. Suwaryo dkk., (2016) dan Abdelgadir dkk., (2017) menjelaskan bahwa mayoritas masyarakat yang mengalami cedera kepala adalah pada usia 18-40 tahun. Usia 1840 tahun merupakan usia produktif yang memiliki aktifitas yang tinggi sehingga meningkatkan resiko terjadinya cedera kepala.

Penelitian juga mendapatkan lebih dari $70 \%$ cedera kepala terjadi pada lakilaki. Beberapa penelitian lain juga mendapatkan bahwa laki-laki lebih beresiko mengalami cedera kepala (Husnah dkk., 2019; Putra dkk., 2016; Tito \& Saragih, 2018). Cedera kepala dianggap sebagai masalah laki-laki, karena laki-laki lebih sering berpartisipasi dalam kegiatan yang meningkatkan risiko terjadinya cedera kepala (Spani, Braun, \& Van Eldik, 2018).

Tingkat kesadaran (GCS) merupakan data yang sangat penting untuk dikaji pada pasien dengan cedera kepala yang baik digunakan memprediksi mortalitas pasien trauma (Osler dkk., 2016). Hasil penelitian menunjukkan bahwa responden yang memiliki skor GCS rendah, memiliki risiko mortalitas yang lebih tinggi. Kasmaei dkk., (2015) menjelaskan bahwa scor GCS $<9$ sebagai prediktor independen outcome pada pasien cedera kepala. Penelitian pada 46 responden di Unit Gawat Darurat mendapatkan bahwa skor GCS merupakan predictor utama mortalitas pasien cedera kepala (Sumarno dkk., 2016).

GCS berhubungan dengan adanya gangguan struktur atau jaringan otak yang dapat berakibat pada kematian jaringan otak. Jaringan otak yang mengalami kematian merupakan data penting yang perlu dikaji, karena jaringan otak memiliki sifat yang irreversible. Otak adalah pusat pengaturan sistem vital tubuh seperti sietem respirasi dan sistem kardovaskular sehingga apabila terjadi kerusakan atau gangguan pada otak akan mengganggu fungsi sistem sistem tersebut, yang meningkatkan resiko kematian (Sumarno dkk., 2016). Rendahnya skor GCS pada awal pasien masuk IGD menandakan bahwa terdapat gangguan otak yang berat. Beratnya gangguan yang terjadi akan menimbulkan terganggunya kerja otak yang meningkatkan ancaman kematian pasien.

Selain GCS, tekanan darah sistolik juga memiliki pengaruh pada outcome pasien cedera kepala. Imen dkk., (2015) menjelaskan bahwa tekanan darah sistolik $<90 \mathrm{mmHg}$ memiliki hubungan dengan mortalitas pasien cedera kepala berat. Penelitian lain oleh Suwaryo dkk., (2016) mendapatkan bahwa faktor dominan outcome pasien cedera kepala adalah tekanan darah sistolik. Tekanan darah merupakan salah satu data penting untuk memprediksi prognosis pasien cedera kepala. Pasien cedera kepala dengan hipotensi akan memiliki risiko yang lebih tinggi mengalami kematian, hal ini berhubungan dengan aliran darah ke otak yang terganggu (Sumarno dkk., 2016). Tekanan darah dibawah $90 \mathrm{mmHg}$ berhubungan tingkat mortalitas tinggi dan rawatan yang lebih lama (Imen dkk., 2015; Ristanto dkk., 2016). Tekanan darah sistolik yang menurun $(<90 \mathrm{mmHg})$, apabila terjadi secara berlanjut berakibat pada turunnya tekanan perfusi otak/cerebral perfusion pressure (CPP). Cerebral perfusion pressure yang rendah akan menyebabkan timbulnya iskemik dan infark di jaringan otak. Oleh karena itu, tekanan darah harus dipertahankan dalam rentang normal, sehingga CPP juga dalam rentang normal dan iskemik jaringan cerebral dapat dicegah.

Penelitian ini mendapatkan bahwa frekuensi pernapasan tidak memiliki pengaruh terhadap tingkat mortalitas pasien cedera kepala. Hal ini mungkin berhubungan dengan proses terjadinya penurunan saturasi oksigen dan perfusi 
jaringan otak membutuhkan waktu 12-24 jam. Waktu tersebut merupakan kompensasi tubuh terhadap komplikasi yang ditimbulkan tidak seperti cedera paru yang mempunyai efek langsung terhadap saturasi oksigen dan frekuensi pernafasan pada pasien (Suwaryo dkk., 2016).

Hal ini berbeda dengan penelitian Bruijns dkk., (2014) yang mendapatkan bahwa tekanan darah sistolik dan frekuensi pernafasan secara bersamaan merupakan prediktor yang baik untuk mengetahui outcome pasien cedera kepala,. Frekuensi nafas kurang dari 10 kali permenit berhubungan dengan prognosis yang buruk karena perfusi dan oksigenasi yang menurun ke otak atau menunjukkan telah terjadinya efek sekunder peningkatan tekanan intrakranial berupa kompresi serebral terutama pada fase awal cedera kepala. Ankita, Kunkulol, Shaikh, \& Sangle (2015) menjelaskan bahwa prognosis pasien cedera kepala dipengaruhi oleh status oksigenasi pasien saat masuk ke IGD.

Cedera kepala memiliki tingkat kematian yang tinggi. Untuk itu, penilaian awal stasus fisiologis pasien cedera kepala sangat penting dilakukan terutama tingkat kesadaran dan tekanan darah sistolik. Dengan mengobservasi tingkat kesadaran dan status fisiologi dari awal pasien masuk IGD dapat membantu perawat dalam memilah pasien yang memiliki survival rate tinggi, mengoptimalkan pengobatan dan memprediksi risiko mortalitas cedera kepala (Aprilia, 2017).

\section{SIMPULAN DAN SARAN}

Skor GCS dan tekanan darah sistolik dapat memprediksi outcome pasien cedera kepala. Semakin rendah skor GCS, semakin meningkatkan resiko kematian pada pasien cedera kepala sebesar 3,299 kali dan semakin rendah tekanan darah sistolik, semakin meningkatkan risiko mortalitas sebesar 1,044 kali. Disarankan untuk memprioritaskan pasien cedera kepala dengan skor GCS rendah dan tekanan darah sistolik rendah.

\section{UCAPAN TERIMA KASIH}

Penulis mengucapkan terima kasih kepada Direktorat Riset dan Pengabdian Masyarakat Direktorat Jenderal Penguatan Riset dan Pengembangan Kementrian Riset, Teknologi dan Badan Riset dan Inovasi Nasional Republik Indonesia (Kemenristek/BRIN) yang telah memberikan dana hibah penelitian ini.

\section{DAFTAR PUSTAKA}

Abdelgadir, J., Smith, E. R., Punchak, M., Vissoci, J. R., Staton, C., Muhindo, A., ... Haglund, M. M. (2017). Epidemiology and characteristics of neurosurgical conditions at Mbarara regional referral hospital. World Neurosurgery, 102, 526-532.

Ankita, S., Kunkulol, R. R., Shaikh, M., \& Sangle, A. (2015). Hypoxic status and its prognosis in patients with head injury. International Journal of Medical Research \& Health Sciences, 4(3), 662-666.

Aprilia, H. (2017). Gambaran status fisiologis pasien cedera kepala di IGD RSUD Ulin Banjarmasin tahun 2016. Dinamika Kesehatan: Jurnal Kebidanan Dan Keperawatan, 8(1), 237-249. 
Areas, F. Z., Schwarzbold, M. L., Diaz, A. P., Rodrigues, I. K., Sousa, D. S., Ferreira, C. L., ... Walz, R. (2019). Predictors of Hospital Mortality and the Related Burden of Disease in Severe Traumatic Brain Injury: A Prospective Multicentric Study in Brazil. Frontiers in Neurology, 10, 432-439.

Baum, J., Entezami, P., Shah, K., \& Medhkour, A. (2016). Predictors of outcomes in traumatic brain injury. World Neurosurgery, 90, 525-529.

Bruijns, S. R., Guly, H. R., Bouamra, O., Lecky, F., \& Wallis, L. A. (2014). The value of the difference between ED and prehospital vital signs in predicting outcome in trauma. Emergency Medicine Journal, 31(7), 31(7), 579-582.

Guyton, A. C., \& Hall, J. E. (2014). Buku Ajar Fisiologi Kedokteran (12 ed.). Jakarta: EGC.

Husnah, K., Murtala, B., Asriyani, S., Zainuddin, A. A., Mustamir, N., \& Latief, N. (2019). Prediksi Prognosis Penderita Trauma Kapitis Berdasarkan Gambaran CT scan Kepala. Jurnal Kedokteran Brawijaya, 30(4), 297-301.

Imen, R. B., Olfa, C., Kamilia, C., Meriam, B., Hichem, K., Adel, C., ... Noureddine, R. (2015). Factors predicting early outcome in patients admitted at emergency department with severe head trauma. Journal of Acute Disease, 4(1), 68-72.

Kasmaei, V. M., Asadi, P., Zohrevandi, B., \& Raouf, M. T. (2015). An Epidemiologic Study of Traumatic Brain Injuries in Emergency Department. Emergency (Tehran, Iran), 3(4), 141-145.

Kementrian Kesehatan RI. (2019). Laporan Nasional Riskesdas 2018. Jakarta: Badan Penelitian dan Pengembangan Kesehatan.

Osler, T., Cook, A., Glance, L. G., Lecky, F., Bouamra, O., Garrett, M., ... Hosmer, D. W. (2016). The differential mortality of Glasgow Coma Score in patients with and without head injury. Injury, 47(9), 1879-1885.

Putra, D. S. E., Indra, M. R., Sargowo, D., \& Fathoni, M. (2016). Nilai Skor Glasgow Coma Scale, Age, Systolic Blood Pressure (GAP SCORE) Dan Saturasi Oksigen Sebagai Prediktor Mortalitas Pasien Cedera Kepala di Rumah Sakit Saiful Anwar Malang. Jurnal Kesehatan Hesti Wira Sakti, 4(2), $13-28$.

Ristanto, R., Indra, M. R., Poeranto, S., \& Rini, I. S. (2016). Akurasi revised trauma score sebagai prediktor mortality pasien cedera kepala. Jurnal Kesehatan Hesti Wira Sakti, 4(2), 76-90.

Spani, C. B., Braun, D. J., \& Van Eldik, L. J. (2018). Sex-related responses after traumatic brain injury: Considerations for preclinical modeling. Frontiers in Neuroendocrinology, 50, 52-66.

Strnad, M., Borovnik Lesjak, V., Vujanović, V., \& Krizmarić, M. (2017). Predictors of mortality in patients with isolated severe traumatic brain injury. Wiener Klinische Wochenschrift, 129(3-4).

Sumarno, S., Hidajat, M., \& Rini, I. S. (2016). Glasgow Coma Scale (GCS), Tekanan Darah dan Kadar Hemoglobin Sebagai Prediktor Kematian pada Pasien Cedera Kepala. Jurnal Ilmiah Kesehatan Keperawatan, 12(3).

Suwaryo, P. A. W., Wihastuti, T. A., \& Fathoni, M. (2016). Analisis Faktor-Faktor Yang Berhubungan Dengan Outcome Pasien Cedera Kepala Di Igd Rsud Prof. Dr. Margono Soekardjo Purwokerto. Jurnal Ilmiah Kesehatan Keperawatan, 12(3), 154-164.

Tito, A., \& Saragih, S. G. (2018). Perbandingan Glasgow Coma Scale dan 
Bali Medika Jurnal.

Vol 7 No 2, 2020: 1-8

ISSN : 2615-7047

DOI: https://doi.org/10.36376/bmj.v7i2

Gambaran Midline-Shift CT-Scan Kepala sebagai Prediktor Mortalitas Pasien Cedera Kepala. Cermin Dunia Kedokteran, 54(4), 247-249.

Varghese, R., Chakrabarty, J., \& Menon, G. (2017). Nursing management of adults with severe traumatic brain injury: A narrative review. Indian Journal of Critical Care Medicine: Peer-Reviewed, Official Publication of Indian Society of Critical Care Medicine, 21(10), 684. 